\title{
Ophthalmoplegia associated with transorbital penetrating brainstem injury by broken fishing pole
}

This article was published in the following Dove Press journal:

Clinical Ophthalmology

I 2 July 20 I I

Number of times this article has been viewed

\section{Aki Kaneko-Ohtaki \\ Shigeki Machida \\ Takeshi Sugawara \\ Daijiro Kurosaka}

Department of Ophthalmology, Iwate Medical University School of Medicine, Iwate, Japan
Correspondence: Shigeki Machida Department of Ophthalmology, Iwate Medical University, School of Medicine, 19-I Uchimaru Morioka Iwate 020-8505, Japan

Tel +8 I 19 65I 5III (ext 6902)

Fax +81196532864

Email smachida@iwate-med.ac.jp

\begin{abstract}
We report our findings in a case of ophthalmoplegia caused by a transorbital penetrating brainstem injury. An 8-year-old boy was accidentally injured by a broken fishing fiberglass pole which penetrated through the right orbit and entered the brainstem. Magnetic resonance imaging showed a linear wound that entered and passed through the pons obliquely and reached the fourth cerebral ventricle and cerebellar vermis. He had a left-sided hemiplegia and left facial nerve palsy and was diagnosed with "one-and-a-half syndrome". His hemiplegia and left facial nerve palsy resolved in 2 weeks leaving only a left abducens nerve palsy. The eye position and eye movements fully recovered within 3 months. These findings suggest a good prognosis for this type of trauma unless life-threatening changes develop.

Keywords: penetrating orbitocranial trauma, trauma, penetrating orbitocranial injury
\end{abstract}

\section{Introduction}

A rare type of trauma that can affect the eye and be life-threatening is a penetrating orbitocranial injury. ${ }^{1-4} \mathrm{~A}$ foreign body can penetrate into the brain through the superior orbital fissure or optic canal ${ }^{5}$ and cause brainstem injury. ${ }^{6-9}$ Among earlier reports, there is only one case that presented with a gaze palsy associated with a penetrating orbitocranial brainstem injury. ${ }^{6}$ However, in this case, a radiological examination by computed tomography did not detect any signs that accounted for the cause of the ophthalmoplegia. We report a case of ophthalmoplegia caused by a penetrating injury by a broken fishing pole. In our case, magnetic resonance imaging clearly showed a brainstem lesion that was consistent with the clinical manifestations.

\section{Case report}

While playing sword fighting with his sister, an 8-year-old boy was injured by a broken fiberglass fishing pole on December 26, 2006. His sister reported that the broken fishing pole entered his right eye and she pulled it out immediately. He was taken to the emergency room complaining of right ocular pain and nausea. Examination showed that the right eyelid was swollen, and he had horizontal gaze paresis without limitation of abduction of the right eye. He was diagnosed with "one-and-a-half syndrome". He also had a left-sided hemiplegia and left facial nerve palsy.

T2-weighted magnetic resonance imaging (MRI) on December 27, 2006 showed a high intensity signal that passed through the pons obliquely from the right to left side and reached the fourth cerebral ventricle and cerebellar vermis (white arrows in Figure 1). Bright blood signals in the MRI images suggested a small amount of subarachnoid hemorrhage in the right prepontine area. Computed tomography images did not show 


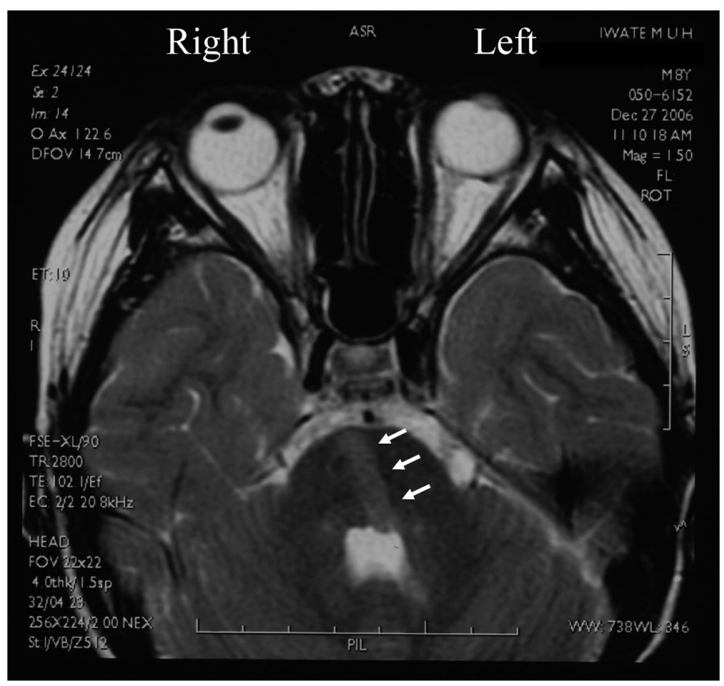

Figure I Magnetic resonance image showing a linear wound (indicated by white arrows) that traverses the pons and reaches the fourth cerebral ventricle and cerebellar vermis.

any signs of fractures or brain hemorrhage. The patient was treated with systemic corticosteroids and antibiotics. He was given $14 \mathrm{mg} /$ day of dexamethasone for the first 3 days. Then, the dosage was tapered, and none was given after day 10 . He quickly recovered from the left-sided hemiplegia and was able to stand 9 days after the injury and walk on day 11 . The leftsided hemiplegia disappeared within 14 days after the injury.

Nine days after the injury, he was referred to us for further ophthalmological examination. On our initial examination, on January 4, 2007, he was found to be esotropic with severe limitation of abduction of the left eye and mild limitation of adductions of both eyes (indicated by arrows, Figure 2A). A subcutaneous hemorrhage was noted at the medial canthus of the right eyelid. There was no loss of sensation in the ophthalmic division of the trigeminal nerve. The direct and indirect light reflexes of the pupil were normal. The esotropic deviation was 30 prism diopters $(\Delta)$ when fixing with the right eye and $65 \Delta$ when fixing with the left eye. Examination with a Hess chart demonstrated that abduction of the left eye was severely limited (Figure 2B).

Binocular single vision was not present because of sensory suppression, and we prescribed saccadic eye movement and fusion training. Three months after the injury, the eye position and eye movements had completely recovered (Figure 3A), which was confirmed by the Hess chart tests and single binocular vision tests (Figure 3B). The left facial nerve palsy improved, leaving a mild lagophthalmos.

\section{Discussion}

Although we could not find any entry wound around the eye at our initial examination 9 days after the injury, a subcutaneous hemorrhage was noted at the medial canthus of the right upper eyelid. This suggested that the fishing pole penetrated the medial canthus of the eyelid and conjunctiva nasal to the right globe. It then passed through the orbit but did not injure the globe or the extraocular muscles. We believe that the pole passed through the superior orbital fissure and reached the brainstem. The direction of the high signal intensity in the MRI images was consistent with this direction of the penetrating pole. The pole injured the pyramidal tract on the right side, resulting in the left-sided hemiplegia. Because the high intensity lesion passed through the pons obliquely, the pole most likely passed through the nucleus of the ipsilateral (left side) abducens nerve, axons of the ipsilateral facial nerve, pontine paramedian reticular formation (PPRF), and medial longitudinal fascicule (MLF). The clinical findings indicated that the right pyramidal tract, left PPRF, left MLF, and the left sixth and seventh nerves were affected.

The patient completely recovered from the left-sided hemiplegia and ophthalmoplegia, without any neurological defects, within 3 months. Several factors may have
A

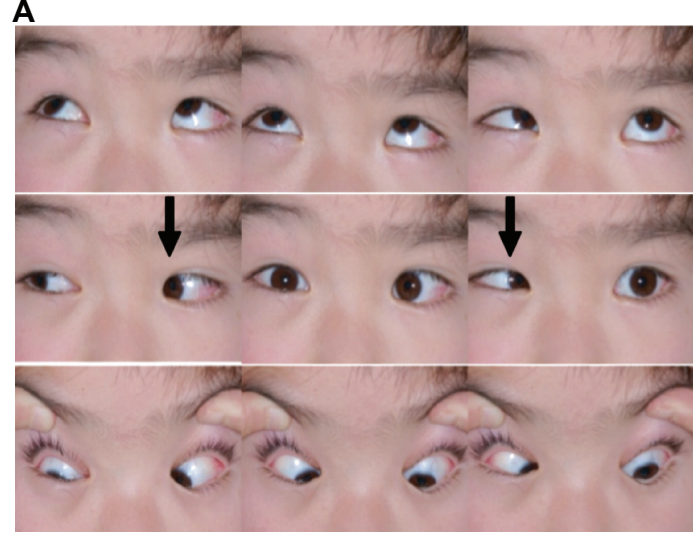

B

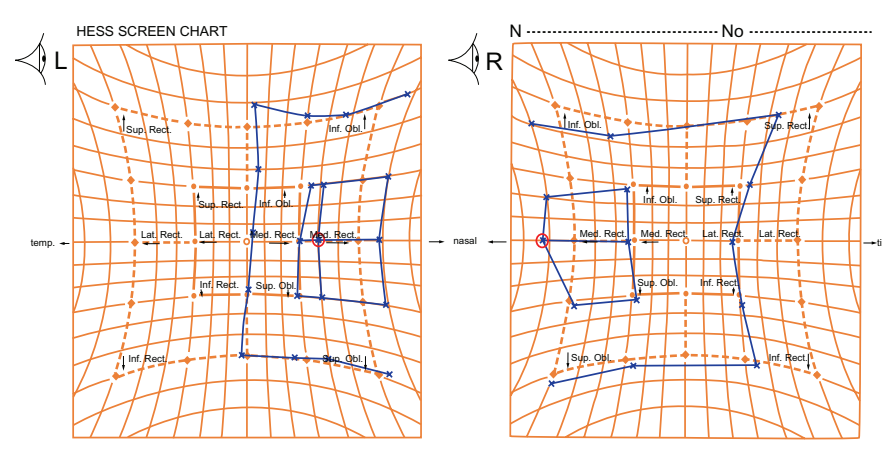

Figure 2 External photograph of the eyes, and Hess chart, at the initial examination. (A) Esotropia can be seen at the primary eye position. Abduction of the left eye is severely impaired, and adduction is mildly limited in both eyes (indicated by arrows). (B) Hess chart shows esotropia and limitation of abduction of the left eye. 
A

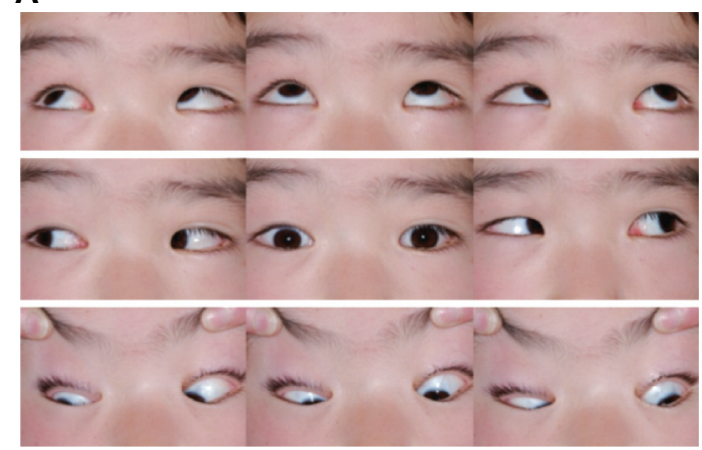

B

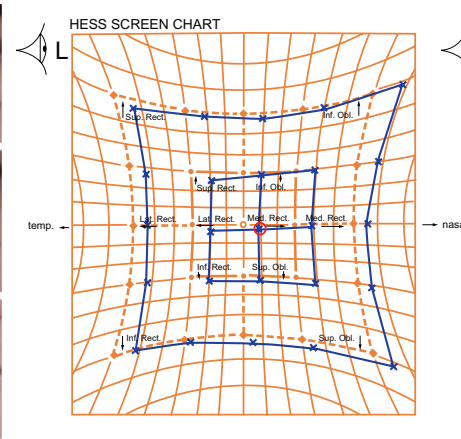

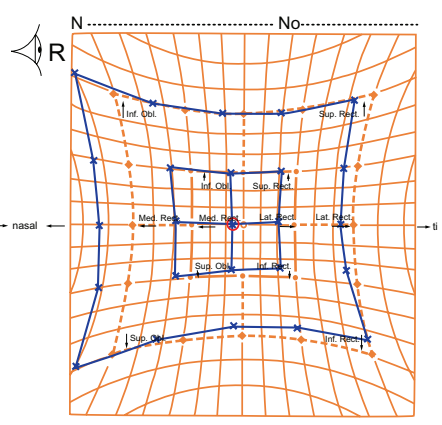

Figure 3 External photograph of the eyes, and Hess chart, three months after the injury. (A) Eye position and eye movements had completely recovered. (B) Hess chart shows recovery of the eye position and movement.

contributed to the good outcome in our case. First, the patient was young. Hungerford reported a neurological recovery in a 22-year-old patient with a penetrating orbitocranial injury by a fencing foil. ${ }^{6}$ Although his patient had a hemiplegia and horizontal gaze palsy, these signs rapidly resolved after starting corticosteroids. Both cases indicate that age may be an important factor for the prognosis. Second, the diameter of the fishing pole was small so that secondary lesions, such as brain hemorrhage, did not occur except for the mild subarachnoid hemorrhage. Third, cerebral edema manifested as high intensity signals in the MRI image might have compressed the abducens and facial nerves, PPRF, MLF, and the pyramidal tract. As the edema subsided, dysfunction related to these lesions quickly recovered, which could account for the good outcome from the ophthalmoplegia and hemiplegia.

The patient was treated with corticosteroids, which might have enhanced the resolution of the cerebral edema. Corticosteroids have been used to treat severe brain injury, although its effectiveness is controversial. In animal models with brain injury, high dose corticosteroids have been shown to reduce post-traumatic neuronal degeneration and improve outcome. ${ }^{10}$ However, a recent randomized clinical trial failed to demonstrate an effectiveness of corticosteroids in adults with head injury. ${ }^{11}$

Our findings indicate that this type of ophthalmoplegia in young individuals can be resolved without surgical intervention, suggesting good prognosis unless life-threatening events occur.

Clinical Ophthalmology

\section{Publish your work in this journal}

Clinical Ophthalmology is an international, peer-reviewed journal covering all subspecialties within ophthalmology. Key topics include: Optometry; Visual science; Pharmacology and drug therapy in eye diseases; Basic Sciences; Primary and Secondary eye care; Patient Safety and Quality of Care Improvements. This journal is indexed on

\section{Acknowledgment}

We presented this case at the International NeuroOphthalmology Society 2008 (Napa, CA, USA). We thank Dr Yoji Takahashi for valuable suggestions on this case.

\section{Disclosure}

The authors report no conflicts of interest in this work.

\section{References}

1. Bard LA, Jarrett WH. Intracranial complications of penetrating orbital injuries. Arch Ophthalmol. 1964;71:332-343.

2. Miller CF, Brodkey JS, Colombi BJ. The danger of intracranial wood. Surg Neurol. 1977;7:95-103.

3. Doucet TW, Harper DW, Rogers J. Penetrating orbital foreign body with intracranial involvement. Ann Ophthalmol. 1983;15:325-327.

4. Michon JJ, Miller NR. Management of combined penetrating intraorbital and intracranial trauma. Arch Ophthalmol. 1993;111:438-439.

5. Smely C, Orszagh M. Intracranial transorbital injury by a wooden foreign body: re-evaluation of CT and MRI findings. Br J Neurosurg. 1999;13:206-211.

6. Hungerford J. A penetrating orbitocranial injury presenting as a gaze palsy. J Neurol Neurosurg Psychiatry. 1982;45:1072-1073.

7. Ildan F, Baðdatoðlu H, Boyar B, Doðanay M, Cetinalp E, Karadayi A. The nonsurgical management of a penetrating orbitocranial injury reaching the brain stem: case report. J Trauma. 1994;36:116-118.

8. Matsuyama T, Okuchi K, Nogami K, Hata M, Murao Y. Transorbital penetrating injury by a chopstick. Case report. Neurol Med Chir. 2001; 41:345-348.

9. Noda E, Inoue M, Yoshikawa-Kobayashi I, Nagamoto T. Perforating eyelid injury extending to the brain stem in a 17-year-old woman: a case report. J Med Case Reports. 2010;4:18

10. Hall ED. High dose glucocorticoid treatment improves neurological recovery in head-injured mice. $J$ Neurosurg. 1985;62:882-887.

11. CRASH trial collaborators. Final results of MRC CRASH, a randomized placebo-controlled trial of intravenous corticosteroid in adults with head injury - outcomes at 6 months. Lancet. 2005;365:1957-1959.

\section{Dovepress}

PubMed Central and CAS, and is the official journal of The Society of Clinical Ophthalmology (SCO). The manuscript management system is completely online and includes a very quick and fair peer-review system, which is all easy to use. Visit http://www.dovepress.com/ testimonials.php to read real quotes from published authors. 